\title{
Home and community care for older people in urban China: receipt of services and sources of payment
}

\author{
Bo $\mathrm{Hu}^{1} \quad$ Bingqin $\mathrm{Li}^{2} \quad$ Jing Wang ${ }^{3} \quad$ Cheng $\mathrm{Shi}^{4}$
}

1 Care Evaluation and Policy Centre, Department of Health Policy, London School of Economics and Political Science, UK. Corresponding author. Address: 8.01G Pankhurst House, Clement's Inn, London WC2A 2AZ, United Kingdom. Tel: +44 02078494649; Email: b.hu@1se.ac.uk.

2 Social Policy Research Centre, University of New South Wales, Australia

3 Institute of Sociology, Chinese Academy of Social Sciences, China

4 China Social Security Research Centre, School of Labour and Human Resources, Renmin University, China

The authors report no conflicts of interest. Ethical approval is not needed for the research. 


\begin{abstract}
This study investigates the characteristics of Chinese older people receiving home and community care and the factors associated with the sources of payment for care services. The data come from the Social Survey of Older People in Urban China, which collected information from a random sample of 3,247 older people aged 60 and over in 10 large cities in different regions of China in 2017. Anderson's behavioural model of care utilisation is used to guide the analyses. The study identifies four striking features of the Chinese social care system. First, although disabilities are a significant predictor of receiving care, a large proportion of care recipients do not have disabilities. Second, perceived proximity of care is the most important predictor, which implies high elasticity of demand for care services with regard to perceived distance and the great geographical inequality of care resources in the cities. Third, the government policies support the use of the internet to facilitate care access, but the enabling effect of the internet among older people is limited. Finally, sources of payment for care differ significantly according to people's age, living arrangements, disability and level of education. We argue that the government should consider shifting the focus of financial support from service providers to care recipients in the future.
\end{abstract}

Keywords: Home and community care, service use, payment of care, older people, China 
What is known about this topic:

- Home and community care services, which have a short history in China, are welldeveloped in provincial capitals and megacities after a decade of policy reforms.

- In developed countries, receipt of home and community care is driven by people's care needs.

- The internet provides an important channel through which people access information on public services.

What this paper adds:

- Receipt of care is more strongly driven by perceived proximity of care than care needs in urban China.

- Use of the internet does not automatically lead to the use of home and community care; it only facilitates care access for a small group of older people with the 'right' level of IT skills.

- Due to the stringent eligibility criteria for government support, a small proportion of older people receive publicly-funded care, whereas most people must pay for care themselves or rely on financial support from relatives. 


\section{Introduction}

Home and community care provided by professional caregivers is crucial to the wellbeing of older people. High-quality services compensate for declines in physical and cognitive functioning (Vergrugge \& Jette, 1994), provide support for social participation, and help older people live independently for longer in their homes (Tesch-Romer \& Wahl, 2017). China relies heavily on unpaid care or informal care provided by family members to meet older people's needs, but this approach is unlikely to be sustainable in the long run. The United Nations (2017) has projected that the old-age dependency ratio in China will increase from 14.5 to 35.3 in the next two decades. Hu (2019) has projected that the number of people who need care will double and reach 82.6 million people by 2035. Furthermore, low fertility rates in the Chinese population will lead to a continued decrease in the unpaid care resources that are accessible to older people (Zhang et al., 2012).

The stark contrast between the rising demand for unpaid care and its decreasing supply poses a serious risk of unmet needs in old-age care (Peng et al., 2015). Faced with this challenge, the Chinese government has introduced a series of policies to develop the social care sector. Massive amounts of resources have been directed to this sector in the past decade to expand the service capacity. In particular, the government plans to build a system where 'home care is the foundation, community care provides the necessary support, and residential care is supplementary' (State Council, 2013).

After the decade-long reforms and capacity building, a comprehensive policy framework is well-developed in most provincial capitals (i.e., the capital cities of provinces), and there has been a surge in the number of social care providers serving older people living in the community. It is high time to take stock of the developments in the Chinese social care system, the starting point for which entails answering two crucial questions: who is receiving social 
care services, and who is paying for them? Guided by these two questions, this study investigates the determinants of social care receipt and the sources of care payment in the older population using data collected from 10 large cities located in different regions of China. The discussion focuses on home and community care. Informal care for Chinese older people has already been studied in previous research (Hu \& Ma, 2018, Hu \& Wang, 2019). Therefore, it will not be the focus of this paper. Residential care relates to different policies and is financed separately in some localities, so it is also beyond the scope of the investigation here.

\section{Home and Community Care Policy in China}

Although the Chinese government laid out its strategy to develop home and community-based services as early as 2006 (Ten Ministries, 2006), it was in the $12^{\text {th }}$ Five-Year Forward Plan that the central role of these services in the Chinese social care system was formally established (State Council, 2011). Up to now, these services have mainly been provided by not-for-profit organisations or private enterprises (Xu \& Chow, 2011). The government, in contrast, has prioritised its efforts to cultivate and regulate the care market.

The government has stipulated that providers should focus on five types of home and community care: help with bathing, help with housework, help with meals, help with walking outside the house, and day care services (State Council, 2013, State Council, 2016). The first two are home-based services. Older people can ask service providers to deliver meals to their homes (i.e. meals-on-wheels) or can eat in designated community canteens or local restaurants at subsidised prices.

The central government formulates the overall strategy and policy, whereas local governments implement the policy. Since China has a highly decentralised fiscal system, local governments provide financial resources to the social care sector from their own budgets (Mor, 2014, p.17). To increase service capacity, the central government has published a range of policies that 
encourage service providers to enter the care market. Providers can receive local government funding that covers the initial investment. In some cities, the municipal governments also offer subsidies to care providers to help with operating costs (Tong \& Wang, 2015). In addition, providers also receive tax relief and interest rate reductions on their loans (State Council, 2013).

The central government's strategy in capacity building is interpreted differently by different local authorities. Two models define the composition of social care services. The first is the '9064' model: 90\% of older people live independently in their own homes or receive home care, $6 \%$ receive community care and the rest (4\%) live in a care home. The other is the ' 9073 ' model, with the proportions of older people in the three settings being $90 \%, 7 \%$ and $3 \%$, respectively (Li \& Otani, 2018). In practice, the expansion of service capacity has been highly uneven across the country. The development of the social care system requires enormous financial investment from local governments. Different regions vary markedly in terms of economic development. Regions that are more economically developed have more tax revenue, and local governments thus have more financial resources to develop health and social care services (Jia et al., 2014). Furthermore, large cities and provincial capitals are granted extra funding by the central government, in the hope that the social care sector in these cities can set an example for other parts of the country (Ministry of Civil Affairs, 2016). This difference in funding results in a great divide in care availability: while the number of providers has increased greatly in provincial capitals or large cities, care services remain scarce in poor rural counties and villages (Feng et al., 2012).

To further cultivate the care market, information and communication technology (ICT) has recently been added to the government agenda. Under the banner of the 'Internet Plus' strategy, a policy was published in 2016 that spelled out a plan to harness the potential of ICT to improve the quality of social care for older people and to match care provision with demand. The government aims to widen the use of cloud computing, the internet of things, and big data in 
the social care sector, promote innovation in the delivery of social care services (State Council, 2016), and encourage care agencies to use the internet as a platform for service provision (Three Ministries, 2017).

In contrast to the massive financial investment devoted to market cultivation and capacity building, limited resources are reserved for directly supporting care users. Local governments leave the task of care provision to enterprises or non-government organisations, and the majority of service users are expected to assume the costs of care. The government steps in only when older people have no other resources (e.g. a family caregiver and pension income). In practice, this limited support is reflected in the stringent eligibility criteria for government support. Financial support by the government is confined to older people with disabilities and low incomes and is subject to assessment and verification by third-party specialists (Municipal Government of Shanghai, 2016). In some cities, only older people above a certain age are entitled to government support.

Financial support from the government may take the form of vouchers or cash-for-care benefits. These arrangements are designed to allow more user choice and autonomy. In a voucher scheme, people apply for vouchers from the Residential Committee in the local community, which passes on the applications to the municipal government. The Residential Committee is the governing authority of a community and plays a central role in coordinating care delivery (Xu \& Chow, 2011). Older people with vouchers can purchase services from competing providers authorised by the government. Beijing, the capital city of China, and Hefei, a provincial capital in Anhui Province, have adopted this approach (Municipal Government of Beijing, 2009, Ma \& Ye, 2015). In the case of cash-for-care benefits, local governments transfer money to the bank accounts of eligible care users. The funding for old age care in Tianjin is a typical case of the cash-for-care approach (Municipal Government of Tianjin, 2017). There are also cases where local governments pay for services on behalf of eligible users 
in advance. People receive services either partially or totally free of charge from the providers. Hangzhou, a provincial capital in Zhejiang Province, is an example of this approach (Municipal Government of Hangzhou, 2013).

The amount of government support for care recipients varies in different cities. In Tianjin, for instance, support is only available to older people living below the poverty line, and those with a mild, moderate or severe disability receive annual cash support of $¥ 2,400$ ( $\$ 360)$, $¥ 4,800$ (\$720) or ¥7,200 (\$1080), respectively (Municipal Government of Tianjin, 2017). In Hangzhou, disabled older people whose annual income is below $¥ 11,004(\$ 1,619)$ are entitled to $¥ 4,800$ (\$706) worth of services each year. Disabled older people whose annual income is below $¥ 36,000(\$ 5,294)$ per year are entitled to $¥ 1,000$ (\$150) worth of services each year (Municipal Government of Hangzhou, 2013).

\section{Determinants of Care Receipt: A Literature Review}

A number of studies conducted in developed countries have investigated the determinants of receiving home and community care. Due to its short history in the Chinese welfare system, the empirical evidence regarding the determinants of care receipt in this country is limited. The exception is Li et al.'s (2017) work, which investigated this issue in Shanghai, a city that has spearheaded the development of social care services since the early 2000s (Wu et al., 2005).

Most previous studies have used the behavioural model of care utilisation to guide their analyses. According to this framework, receipt of social care is driven by three groups of factors: need factors, predisposing factors, and enabling factors (Anderson, 1995, Anderson \& Newman, 2005). Need is the most immediate reason for using social care. The existing studies have consistently confirmed the central role of care needs in driving home care receipt (Stoddart et al., 2002, Larsson et al., 2006, Blomgren et al., 2008, Bolin et al., 2008, Murphy et al., 2015, Vlachantoni et al., 2015). 
The predisposing factors and enabling factors that have a significant impact on social care receipt vary from one country to another (Otero et al., 2003, Meinow et al., 2005, Avlund et al., 2008, Hammar et al., 2008). The predisposing factors are the individual-level characteristics (such as age, gender and marital status) that affect people's propensity to receive social care. The enabling factors are the personal means (such as income and education), knowhow, and care resources that facilitate service access (Anderson \& Newman, 2005). The varied impacts of these two types of factors reported in the literature suggest that individual characteristics and the socioeconomic status of care recipients are highly heterogeneous across different countries (Genet et al., 2011).

Use of the internet is a factor that has received little theoretical attention so far, and no empirical research has been conducted to investigate its impact on social care receipt. In the information age, the internet is pivotal in people's lives, as activities such as shopping, communication, searching for information, and entertainment are increasingly taking place online. Older people are the fastest growing group of internet users worldwide: $58 \%$ of older people in the UK (Age UK, 2016) and 67\% in the US (Anderson \& Perrin, 2017) are internet users. With the growth of the digital economy in China, the internet has become an important channel through which people access information on, and complete transactions for, various services (Hong, 2017, Woetzel et al., 2017). Health and social care services are no exception. Therefore, our hypothesis is that use of the internet has an enabling effect and facilitates the receipt of home and community care in the Chinese older population.

\section{Research methods}

Data

This study is based on secondary analyses of existing survey data. The data come from the Social Survey of Older People in Urban China conducted in 2017 (Zhu et al., 2018). Following 
a multistage sampling design, the survey collected information on a random sample of 3,247 older people aged 60 and over from 10 provincial capitals or megacities in different regions of China (table 1). In each city, the primary sampling units were communities. The sampling of communities followed the probability proportional to size (PPS) approach. A total of 197 urban communities were sampled. In each community, the systematic sampling method was used to select a random sample of households. For each selected household, one older person was randomly chosen for a face-to-face structured interview, which took place at the person's home. Details of the data collection, informed consent, and research ethics have been reported elsewhere (Zhu et al., 2018). The dataset and questionnaire used in this study is publicly available (https://osf.io/asnwp/).

Table 1 Background information of the 10 Chinese cities sampled in the survey

\begin{tabular}{cccc}
\hline City & Province & Region & Sample size \\
\hline Beijing & Beijing & North China & 507 \\
Tianjin & Tianjin & North China & 400 \\
Ha'erbin & Heilongjiang & Northeast China & 205 \\
Shanghai & Shanghai & East China & 506 \\
Nanjing & Jiangsu & East China & 201 \\
Wuhan & Hubei & Middle China & 205 \\
Xi'an & Shaanxi & West China & 204 \\
Chongqing & Chongqing & West China & 408 \\
Guangzhou & Guangdong & South China & 410 \\
Shenzhen & Guangdong & South China & 201 \\
\hline Total & & & 3,247
\end{tabular}

Dependent variables

Regression analyses were conducted to examine the determinants of care receipt and sources of care payment. Four questions in the survey asked older people whether they had used one or more of the four types of care: help with bathing, help with meals, help with housework, and day care services. The survey did not ask about help with walking outside the house. We created two receipt of care variables. The first is a binary variable. Older people who had used any of the four services were coded as 1 , and those who had not used any of these services were coded as 0 . The second is a count variable, which adds up the total number of services older people 
had used. The values of the variable range from 0 to 4 . For service recipients, the questionnaire asked them who had paid for their services. Based on their replies, we created a source of payment variable with three categories: payment by care recipients, payment by other relatives (children, grandchildren or siblings), and government support.

\section{Independent variables}

The determinants of social care receipt and sources of payment were selected into the regression models based on the behavioural model discussed in the previous section. We identified two care needs variables in the dataset: self-perceived need and functional limitations. The survey asked older people whether they needed care from other people. We created a selfperceived need variable with binary categories $(0=$ no; $1=y e s)$. The survey collected information on people's ability to perform activities of daily living (ADL) and instrumental activities of daily living (IADLs). There were six ADL questions (eating, dressing, using the toilet, getting out of bed, moving around indoors, and bathing) and six IADL questions (cooking, washing clothes, cleaning the floor, shopping, making a phone call, and managing money). For each ADL or IADL task, respondents were given three options: 'I can do it by myself', 'I have difficulty doing it', and 'I cannot do it'. Those people who reported the latter two situations regarding any of the ADL or IADL tasks were treated as having an ADL or IADL disability, respectively. The Cronbach's alpha for the six ADL items is 0.81 , and that for the six IADL items is 0.88 . Then, we created a need variable with three categories: independence (neither ADL nor IADL disabilities), IADL disabilities only, and ADL disabilities. Older people's loss of ability to perform daily activities has a hierarchy: an ADL disability indicates a more severe disability than an IADL disability (Kingston et al., 2012).

Seven predisposing factors were identified in the dataset: age, gender, marital status, living arrangements, number of children, education, and geographical location. The levels of 
education reported by the older people were: no formal education, primary education, junior secondary education, high school education, college degree, undergraduate, and postgraduate. We combined these levels into a variable with two categories: junior secondary education or below and high school education or above. The survey asked about older people's marital status and living arrangements. We created a variable with four categories: single people who live alone, single people who live with others in the same household, married couples living alone, and married couples living with others. Single older people include those who are single and have never been married or are divorced or widowed. The 10 cities are located in six different regions of China (table 1). We created a geographical location variable with three categories: North and Northeast China, East and Southeast China, and Middle and West China.

Four enabling factors were identified in the dataset: household income, perceived proximity of care services, receipt of informal care, and use of the internet. Household income is a continuous variable. Perceived proximity of care is a dichotomised variable, which was coded as 1 if an older person reported that there was a service provider near his or her home and as 0 otherwise. The receipt of informal care variable was also dichotomised ( $0=$ no; $1=y e s)$.

Older people were asked whether they used the internet. We created a binary variable that was coded as 1 if they answered 'yes' and 0 otherwise. Participants who reported internet use were then asked whether they used it for the following purposes: online entertainment (watching films or TV shows), watching news or chatting with friends, and online shopping. The three questions were not mutually exclusive, so a respondent might report multiple online activities. We created three dichotomised variables $(0=$ no; $1=$ yes $)$.

\section{Statistical analyses}

Communities differ considerably across China in terms of economic development and policy implementation. Some community-level characteristics were not collected in the survey but 
might have significant impacts on care receipt. We built two-level regression models with random effects to correct for the potential bias in coefficients caused by the community-level unobserved heterogeneity (Rabe-Hesketh \& Skrondal, 2012). For the receipt of care, count of services, and sources of payment variables, we built two-level logistic, Poisson, and multinomial logistic regression models, respectively. We conducted the likelihood-ratio test of the level-2 random effects, which shows the magnitude of the community-level heterogeneity and the usefulness of fitting a multilevel model. Twenty-four observations with missing values were excluded from the regression analyses. Stata 14 was used to analyse the data.

Table 2 Number of community-dwelling older people receiving social care services

\begin{tabular}{|c|c|c|}
\hline & Number of people & Proportion \\
\hline \multicolumn{3}{|l|}{ Help with meals } \\
\hline No & 3,028 & $93.3 \%$ \\
\hline Yes & 219 & $6.7 \%$ \\
\hline \multicolumn{3}{|l|}{ Help with bath } \\
\hline No & 3,143 & $96.8 \%$ \\
\hline Yes & 104 & $3.2 \%$ \\
\hline \multicolumn{3}{|l|}{ Help with housework } \\
\hline No & 2,995 & $92.2 \%$ \\
\hline Yes & 252 & $7.8 \%$ \\
\hline \multicolumn{3}{|l|}{ Day care } \\
\hline No & 3,151 & $97.0 \%$ \\
\hline Yes & 96 & $3.0 \%$ \\
\hline \multicolumn{3}{|l|}{ Any care services } \\
\hline No & 2,806 & $86.4 \%$ \\
\hline Yes & 441 & $13.6 \%$ \\
\hline \multicolumn{3}{|l|}{ Number of care services } \\
\hline 1 & 282 & $63.9 \%$ \\
\hline 2 & 105 & $23.8 \%$ \\
\hline 3 & 37 & $8.4 \%$ \\
\hline 4 & 17 & $3.9 \%$ \\
\hline \multicolumn{3}{|l|}{ Sources of payment } \\
\hline Care recipients & 278 & $64.7 \%$ \\
\hline Other relatives in the family & 107 & $24.9 \%$ \\
\hline Government support & 45 & $10.5 \%$ \\
\hline Sample size & & \\
\hline Number of communities & & \\
\hline
\end{tabular}

Note: There are 11 missing values in the sources of payment variable. 


\section{Research findings}

Table 2 shows the number of older people receiving home and community care in the sample. Help with housework has the highest proportion of service receipt, with $7.8 \%$ of older people $(n=252)$ using this service. This item is followed by help with meals $(6.7 \%, n=219)$. The proportions of older people receiving help with bathing and day care services are $3.2 \%(n=104)$ and $3.0 \%(n=96)$, respectively. Some older people seem selective in terms of the types of care they choose to receive. For instance, 24 people in the sample received help with bathing but did not receive any other types of care. In total, 441 older people reported receiving home and community care, among which $63.9 \%(\mathrm{n}=282)$ reported receiving only one type of service and $12.3 \%(n=54)$ reported receiving more than two types of services. A total of $64.7 \%(n=348)$ paid for the services themselves, $24.9 \%(n=107)$ reported that other relatives in the family paid for these services, and $10.5 \%(n=45)$ received financial support from the government, including vouchers, cash-for-care benefits, and services provided free of charge.

Table 3 shows the sample characteristics broken down according to whether or not they received social care. Over half of the sample $(n=1,822)$ were aged between 60 and 69 , and $56.2 \%$ $(n=1,825)$ were females. Three-quarters of the older people $(n=2,422)$ were married, and $5.9 \%$ ( $\mathrm{n}=192)$ were single and living alone. A total of 2,037 were living with other people in the same household, among whom an overwhelming majority $(n=1,930)$ were living with their children. Approximately $27.5 \%$ of older people had finished high school or university education. Regarding care needs and disabilities, $9.3 \%$ of the older people reported having care needs, and $20.7 \%$ reported having ADL or IADL disabilities. The proportions are much higher among those receiving social care. A total of $54.9 \%$ of older people and $92.3 \%$ of care recipients reported that there were service providers near their home. 
Table 3 Sample characteristics

\begin{tabular}{|c|c|c|c|}
\hline & Not Receiving care & Receiving care & Entire sample \\
\hline & \multicolumn{3}{|c|}{ Proportions or means } \\
\hline \multicolumn{4}{|l|}{ Predisposing factors } \\
\hline \multicolumn{4}{|l|}{ Age } \\
\hline $60-69$ & $56.9 \%$ & $51.0 \%$ & $56.1 \%$ \\
\hline $70-79$ & $28.5 \%$ & $29.7 \%$ & $28.6 \%$ \\
\hline $80+$ & $14.6 \%$ & $19.3 \%$ & $15.2 \%$ \\
\hline \multicolumn{4}{|l|}{ Gender } \\
\hline Female & $55.4 \%$ & $61.7 \%$ & $56.2 \%$ \\
\hline Male & $44.7 \%$ & $38.3 \%$ & $43.8 \%$ \\
\hline \multicolumn{4}{|l|}{ Living arrangement } \\
\hline Single living alone & $5.9 \%$ & $6.4 \%$ & $5.9 \%$ \\
\hline Single living with others & $18.7 \%$ & $23.8 \%$ & $19.4 \%$ \\
\hline Married couples living alone & $31.8 \%$ & $27.9 \%$ & $31.3 \%$ \\
\hline Married couples living with others & $43.6 \%$ & $42.0 \%$ & $43.4 \%$ \\
\hline Number of children & 2.0 & 2.0 & 2.0 \\
\hline \multicolumn{4}{|l|}{ Education } \\
\hline Secondary education & $72.6 \%$ & $71.7 \%$ & $72.5 \%$ \\
\hline High school or above & $27.4 \%$ & $28.3 \%$ & $27.5 \%$ \\
\hline \multicolumn{4}{|l|}{ Region of China } \\
\hline North \& Northeast & $34.9 \%$ & $30.2 \%$ & $34.3 \%$ \\
\hline East \& Southeast & $40.8 \%$ & $39.2 \%$ & $40.6 \%$ \\
\hline Middle \& West & $24.3 \%$ & $30.6 \%$ & $25.2 \%$ \\
\hline \multicolumn{4}{|l|}{ Need factors } \\
\hline \multicolumn{4}{|l|}{ Self-reported need } \\
\hline No & $92.0 \%$ & $82.5 \%$ & $90.7 \%$ \\
\hline Yes & $8.0 \%$ & $17.5 \%$ & $9.3 \%$ \\
\hline \multicolumn{4}{|l|}{ Disability } \\
\hline Independent & $81.6 \%$ & $65.3 \%$ & $79.4 \%$ \\
\hline IADL disability only & $12.3 \%$ & $18.6 \%$ & $13.2 \%$ \\
\hline ADL disability & $6.1 \%$ & $16.1 \%$ & $7.5 \%$ \\
\hline \multicolumn{4}{|l|}{ Enabling factors } \\
\hline \multicolumn{4}{|l|}{ Proximity of care } \\
\hline No & $51.0 \%$ & $7.7 \%$ & $45.1 \%$ \\
\hline Yes & $49.0 \%$ & $92.3 \%$ & $54.9 \%$ \\
\hline Household income (10,000 Yuan) & 10.7 & 12.1 & 10.9 \\
\hline \multicolumn{4}{|l|}{ Receipt of informal care } \\
\hline No & $93.0 \%$ & $87.3 \%$ & $92.2 \%$ \\
\hline Yes & $7.0 \%$ & $12.7 \%$ & $7.8 \%$ \\
\hline \multicolumn{4}{|l|}{ Use of internet } \\
\hline No & $45.4 \%$ & $47.6 \%$ & $45.7 \%$ \\
\hline Yes & $54.6 \%$ & $52.4 \%$ & $54.3 \%$ \\
\hline \multicolumn{4}{|l|}{ Online entertainment } \\
\hline No & $75.8 \%$ & $70.3 \%$ & $75.0 \%$ \\
\hline Yes & $24.2 \%$ & $29.7 \%$ & $25.0 \%$ \\
\hline \multicolumn{4}{|l|}{ Online shopping } \\
\hline No & $94.6 \%$ & $90.7 \%$ & $94.0 \%$ \\
\hline Yes & $5.5 \%$ & $9.3 \%$ & $6.0 \%$ \\
\hline \multicolumn{4}{|l|}{ Online chat or news } \\
\hline No & $46.0 \%$ & $47.6 \%$ & $46.2 \%$ \\
\hline Yes & $54.0 \%$ & $52.4 \%$ & $53.8 \%$ \\
\hline Sample size & 2,806 & 441 & 3,247 \\
\hline
\end{tabular}


Table 4 Determinants of receiving social care for older people in urban communities

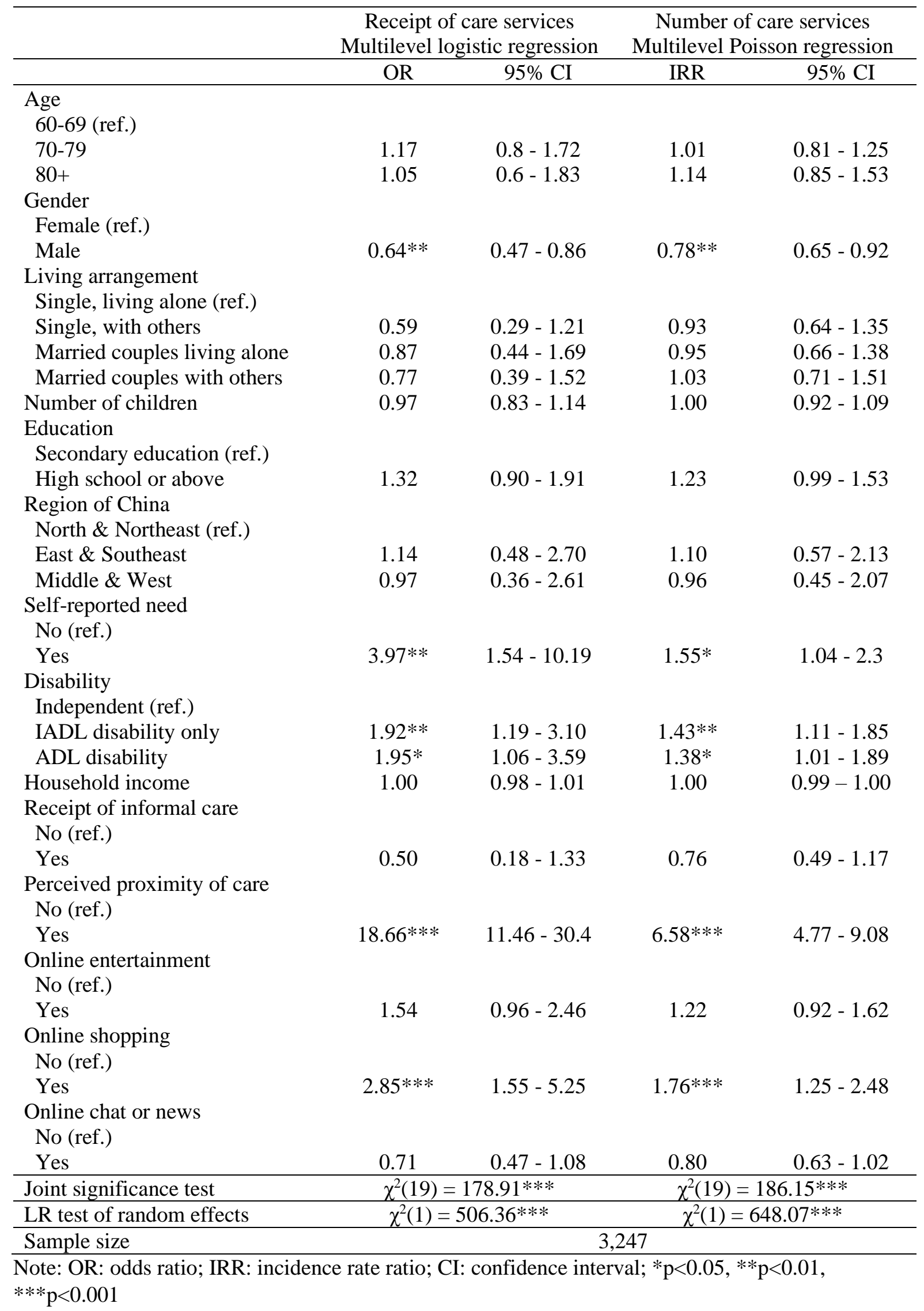


The regression analyses show that females are more likely than males to receive care (columns 2 and 3, table 4). People with self-reported needs and functional limitations have a higher likelihood of receiving care services. Perceived proximity of care is strongly associated with care receipt. For older people with services in the vicinity, their odds of receiving care are 18.8 times higher than the odds of older people without services in the vicinity. The binary internet use variable is not a statistically significant predictor (not shown in this table). Older people who shop online have a significantly higher likelihood of care receipt, but other online activities are not associated with the likelihood of care receipt. The likelihood of care receipt does not differ significantly between different regions.

The regression results concerning the total number of services present a similar picture (columns 4 and 5, table 4). Females and older people with care needs receive a higher number of services. Holding all other variables constant, not having service providers in the vicinity is associated with an $85 \%$ decrease in the expected number of services used. For both the multilevel logistic and the multilevel Poisson models, the results of the likelihood ratio test are statistically significant. Community-level unobserved heterogeneity should be accounted for in the regression models.

Table 5 shows the factors affecting the sources of payment for older people's care services. Our analyses are confined to care recipients and do not include older people not receiving care, so this is a conditional model. Conditional on receipt of home and community care, older people living with relatives are more likely than those living alone to receive financial support from relatives rather than paying for services themselves. Better-educated older people are more likely than those with lower educational qualifications to pay for services themselves rather than receiving financial support from relatives. Older people in the higher age bands and reporting IADL or ADL disabilities are more likely to receive financial support from the government rather than paying for services themselves. 
Table 5 Determinants of sources of payment for social care services

\begin{tabular}{|c|c|c|c|c|}
\hline & \multicolumn{4}{|c|}{$\begin{array}{l}\text { Multilevel multinomial logistic regression } \\
\text { Base outcome: payment by care recipients }\end{array}$} \\
\hline & \multicolumn{2}{|c|}{ Payment by other relatives } & \multicolumn{2}{|c|}{$\begin{array}{l}\text { Payment by government (voucher } \\
\text { cash-for-benefit, or free services) }\end{array}$} \\
\hline & RRR & $95 \% \mathrm{CI}$ & RRR & $95 \% \mathrm{CI}$ \\
\hline \multicolumn{5}{|l|}{ Age } \\
\hline \multicolumn{5}{|l|}{ 60-69 (ref.) } \\
\hline $70-79$ & 1.19 & $0.59-2.42$ & 1.75 & $0.74-4.13$ \\
\hline $80+$ & $2.77 *$ & $1.18-6.53$ & $3.42 *$ & $1.21-9.63$ \\
\hline \multicolumn{5}{|l|}{ Living arrangement } \\
\hline \multicolumn{5}{|l|}{ Single, living alone (ref.) } \\
\hline Single, with others & $6.27 *$ & $1.48-26.56$ & 1.31 & $0.35-4.96$ \\
\hline Married couples living alone & 1.02 & $0.22-4.76$ & 0.95 & $0.27-3.43$ \\
\hline Married couples with others & $6.07 *$ & $1.39-26.48$ & 1.21 & $0.31-4.76$ \\
\hline \multicolumn{5}{|l|}{ Disability } \\
\hline \multicolumn{5}{|l|}{ Independent (ref.) } \\
\hline IADL disability only & $2.26 *$ & $1.04-4.88$ & 1.29 & $0.51-3.27$ \\
\hline ADL disability & $7.67 * * *$ & $3.24-18.15$ & $2.88^{*}$ & $1.04-7.97$ \\
\hline \multicolumn{5}{|l|}{ Education } \\
\hline \multicolumn{5}{|l|}{ Secondary education (ref.) } \\
\hline High school or above & $0.36 * *$ & $0.16-0.78$ & 0.50 & $0.21-1.21$ \\
\hline Household income & $1.02 *$ & $1.00-1.05$ & 0.97 & $0.92-1.03$ \\
\hline Joint significance test & \multicolumn{4}{|c|}{$\chi^{2}(20)=124.24 * * *$} \\
\hline LR test of random effects & \multicolumn{4}{|c|}{$\chi^{2}(1)=6.43^{*}$} \\
\hline Sample size & \multicolumn{4}{|c|}{430} \\
\hline
\end{tabular}

\section{Discussion}

This study investigated the determinants of social care receipt and sources of care payment among community-dwelling older people in urban China. A large random sample collected from different regions of China enabled us to conduct a detailed investigation into the characteristics of social care recipients and the distribution of care resources in the population. The multicity design means that the research findings reported here should be generalisable to other provincial capitals or large cities in China. Apart from the factors that have already been examined in the international literature, we further investigated the impacts of perceived proximity of care and use of the internet, two factors that have received little attention in previous studies. 
Consistent with the prediction of Anderson's behavioural model and evidence from the US and European countries, this study shows that both self-reported needs and functional limitations are important predictors of care receipt in China. This also concurs with the evidence reported in a previous study conducted in the Jing'an District of Shanghai, China (Li et al., 2017). Perceived proximity of care is found to be the most important predictor of care use, with its effect size being much higher than that of other predictors. Previous research in Belgium, Sweden and Finland shows that older people in higher age groups and living alone are more likely to receive home care (Roelands et al., 2003, Meinow et al., 2005, Larsson et al., 2006, Hammar et al., 2008). However, there is no evidence to suggest that age and living arrangements have a significant impact on care receipt in urban China.

Importantly, a large proportion of older people without self-reported needs or functional disabilities are service users (table 3). China is not the only country with such a pattern of care. Murphy et al. (2015) reported that nearly half of Irish home care recipients do not have any ADL/IADL disabilities. However, the underlying reasons for this pattern differ. In Ireland, many home care users receive financial support from the government, so such a pattern of care receipt reflects a certain degree of service mistargeting. In contrast, $10 \%$ of older people in our sample receive publicly funded care. This figure is consistent with our argument that the eligibility criteria in China are so restrictive that only a small group of people are entitled to government support. Most importantly, this finding means that social care resources in China are not allocated by the government via service targeting as is the case in many developed countries. Instead, the pattern of care receipt takes shape in a private market where demand for care is influenced by the costs of care.

For older people, the costs of care are strongly correlated with the proximity of care facilities. If a day care provider is located far away from an older person's home, the time, energy and transportation costs required to access care will increase greatly. This burden is especially 
difficult for older people with physical disabilities (Metz, 2000). People with care needs may be more aware of the locations of services and thus more likely to choose a service provider close to their home. In addition, if care providers are far away, some services (e.g., meals-onwheels) may not be delivered on time and thus become less appealing to users (Farmer et al., 2010). The dominant role of perceived proximity of care in the Chinese social care system has two implications. First, the elasticity of demand for social care with respect to perceived distance in the older population is high. Local governments should keep this in mind when expanding the service capacity. Second, inequality will emerge if the social care system relies heavily on the market for resource allocation. While older people living close to a care provider have easy access to services, those who are less fortunate must rely on other sources of support or cope with unmet needs.

More than half of the older people in our sample are internet users. We did not find a strong association between use of the internet and use of care, which suggests a limited enabling effect of the internet. Internet use by other family members may also mediate this effect. However, this finding does not suggest that internet use is totally unrelated to care receipt. Instead, we found that the purposes of internet use matter, and the enabling role of the internet is most effective among online shoppers.

Online activities undertaken by internet users are a good indication of their IT skills. Numerous studies have shown that online shopping requires advanced IT skills and experience (Monsuwe et al., 2004, Zhang et al., 2006, Hernandez et al., 2011, Lian \& Yen, 2014). Online shoppers must possess information-searching capabilities and be comfortable with online transactions. This requirement implies that access to the internet at present can only empower a small group of older people with the 'right' level of skills. In light of the 'Internet Plus' strategy recently initiated by the Chinese government, we agree that the internet has great potential in regard to widening care access. However, we argue that government policies should not stop at building 
the IT infrastructure and simply using it as a platform for information sharing. Equipping older people with the necessary IT knowledge and know-how to access social care is equally important.

A notable proportion of older people rely on intra-family support to pay for care. The factors affecting the sources of payment are markedly different from the predictors of care receipt. Both age and living arrangements are strong predictors of receiving financial help from other sources to pay for care. We found that older people living alone are less likely to receive intrafamily support. Previous studies have shown that, all other things being equal, Chinese older people who live alone are less likely to receive unpaid care (Hu \& Ma, 2018) and have weaker emotional ties with relatives (Silverstein et al., 2006). These streams of evidence all point to a similar concern: some older people living alone are deprived of care resources and social support, which leaves them in a vulnerable position and is likely to have grave consequences for their health and well-being in the long run.

Several limitations of this study should be acknowledged. First, the survey did not ask whether people receive help to walk around outside the house, so information on this group of service users is unknown. Second, proximity of care was measured using self-reported information. Objective measurements would be equally useful in future research. Third, the prevalence of self-reported needs, ADL disabilities and IADL disabilities among service recipients is low. One possible reason is that care needs were under-reported in the survey. Further research that focuses on the measurement of needs for home and community care in the Chinese older population will be highly valuable. Finally, the number of older people receiving government support is small, so the regression results relating to this group of people should be treated with caution. For instance, we found that people with a lower income are more likely to receive government support, but such a relationship is not statistically significant. This lack of significance may be because the impact of income has been explained away by the disability 
variable, given the high correlation between disability and income. However, another possibility is that statistical significance cannot be detected with the current sample size.

\section{Conclusion}

In the context of population ageing, a well-developed social care system is vital to the wellbeing of older people with care needs and their family carers. The past decade has seen a proliferation of social care policies and a rapid expansion of service capacity in urban China, which certainly deserves recognition and attention. Nevertheless, this study identified several issues in the Chinese social care system that warrant continuing government regulations and further policy reforms. (1) Care receipt is more strongly driven by perceived proximity of care than by care needs, and many service users do not have care needs. (2) The internet is widely accessible to older people in urban China, but its enabling role is limited. (3) Since government support only covers a small proportion of care recipients, care services may be unaffordable for many disabled older people, which in turn will lead to unmet needs. In the previous decade, substantial resources have been devoted to helping care providers become established in the care market. Looking ahead, the government should gradually shift its focus of support from service providers to care recipients. In particular, it should systematically identify the geographical distribution of older people with care needs, provide training opportunities to improve older people's IT skills, and relax the eligibility restrictions on government support. The locations of care providers in a city should be carefully planned so that high-quality services can reach as many people with care needs as possible. 


\section{References}

Age UK (2016) The internet and older people in the UK: key statistics, Age UK, London.

Anderson, M. \& Perrin, A. (2017) Tech adoption climbs among older adults, Pew Research Center, Washington. Available at: http://www.pewinternet.org/2017/05/17/tech-adoption-climbs-among-olderadults. Accessed on 09 October 2018.

Anderson, R. \& Newman, J. F. (2005) Societal and individual determinants of medical care utilization in the United States. Milbank Quarterly, 83(4), 1-28. https://doi.org/10.1111/j.1468-0009.2005.00428.x.

Anderson, R. M. (1995) Revisiting the behavioural model and access to medical care: Does it matter? Journal of Health and Social Behaviour, 36(1), 1-10. https://doi.org/10.2307/2137284.

Avlund, K., Vass, M., Lund, R., Yamada, Y. \& Hendriksen, C. (2008) Influence of psychological characteristics and social relations on receiving preventative home visits in older men and women. European Journal of Ageing, 5(3), 191-201. https://doi.org/10.1007/s10433-008-0086-4.

Blomgren, J., Martikainen, P., Martelin, T. \& Koskinen, S. (2008) Determinants of home-based formal help in community-dwelling older people in Finland. European Journal of Ageing, 5(4), 335-347. http://doi.org/10.1007/s10433-008-0094-4.

Bolin, K., Lindgren, B. \& Lundborg, P. (2008) Informal and formal care among single-living elderly in Europe. Health Economics, 17(3), 393-409. https://doi.org/10.1002/hec.1275.

Farmer, J., Philip, L., King, G., Farrington, J. \& MacLeod, M. (2010) Territorial tensions: misaligned management and community perspectives on health services for older people in remote rural areas. Health and Place, 16(2), 275-283. https://doi.org/10.1016/j.healthplace.2009.10.010.

Feng, Z., Liu, C., Guan, X. \& Mor, V. (2012) China's rapidly aging population creates policy challenges in shaping a viable long-term care system. Health Affairs, 31(12), 2764-2773. http://doi.org/10.1377/hlthaff.2012.0535.

Genet, N., Boerma, W. G., Kringos, D. S., et al. (2011) Home care in Europe: a systematic literature review. BMC Health Services Research. https://doi.org/10.1186/1472-6963-11-207.

Hammar, T., Pissanen, P. \& Perala, M.-L. (2008) Home-care clients' need for help, and use and costs of services. European Journal of Ageing, 5(2), 147-160. https://doi.org/10.1007/s10433-008-0078-4.

Hernandez, B., Jimenez, J. \& Martin, M. J. (2011) Age, gender and income: do they really moderate online shopping behaviour? Online Information Review, 35(1), 113-133. https://doi.org/10.1108/14684521111113614.

Hong, Y. (2017) Pivot to Internet Plus: molding China's digital economy for economic restructuring? International Journal of Communication, 11, 1486-1506. 
Hu, B. (2019) Projecting future demand for informal care among older people in China: The road towards a sustainable long-term care system. Health Economics, Policy and Law, 14(1), 61-81. https://doi.org/10.1017/S1744133118000221.

Hu, B. \& Ma, S. (2018) Receipt of informal care in the Chinese older population. Ageing and Society, 38(4), 766-793. https://doi.org/10.1017/S0144686X16001318.

Hu, B. \& Wang, J. (2019) Unmet long-term care needs and depression: the double disadvantage of community-dwelling older people in rural China Health and Social Care in the Community, 27(1), 126138. https://doi.org/10.1111/hsc.12630.

Jia, J., Guo, Q. \& Zhang, J. (2014) Fiscal decentralization and local expenditure policy in China. China Economic Review, 28107-122. https://doi.org/10.1016/j.chieco.2014.01.002.

Larsson, K., Thorslund, M. \& Kareholt, I. (2006) Are public care and services for older people targeted according to need? Applying the behavioural model on longitudinal data of a Swedish urban older population. European Journal of Ageing, 3(1), 22-33. https://doi.org/10.1007/s10433-006-0017-1.

Li, F., Fang, X., Gao, J., et al. (2017) Determinants of formal care use and expenses among in-home elderly in Jing'an district, Shanghai, China. PLOS ONE, 12(4), e0176548. https://doi.org/10.1371/journal.pone.0176548.

Li, F. \& Otani, J. (2018) Financing elderly people's long-term care needs: Evidence from China. International Journal of Health Planning and Management, 33(2), 479-488. https://doi.org/10.1002/hpm.2488.

Lian, J.-W. \& Yen, D. C. (2014) Online shopping drivers and barriers for older adults: age and gender differences. Computers in Human Behaviour, 37(August), 133-143. https://doi.org/10.1016/j.chb.2014.04.028.

Ma, G. \& Ye, S. (2015) Local practices of commissioning home and community-based services for older people: Achievement, Challenges and Prospect (zhengfu goumai jujia yanglao fuwu de difangxin shijian: chengxiao, tiaozhan yu zhanwang). Shandong Social Sciences, (7), 125-130.

Meinow, B., Karehold, I. \& Lagergren, M. (2005) According to need? Predicting the amount of municipal home help allocated to elderly recipients in an urban area of Sweden. Health and Social Care in the Community, 13(4), 366-377. https://doi.org/10.1111/j.1365-2524.2005.00570.x.

Metz, D. H. (2000) Mobility of older people and their quality of life. Transport Policy, 7(2), 149-152. https://doi.org/10.1016/S0967-070X(00)00004-4.

Ministry of Civil Affairs (2016) Notification on the financial support for the pilot of the home and community-based care policy reform by the central government (zhongyang caizheng zhichi kaizhan jujia he shequ yanglao fuwu gaige shidian diqu de tongzhi), Ministry of Civil Affairs, Beijing. Available at: http://www.yanglaocn.com/shtml/20161123/1479891002103751.html. Accessed on 9 August 2018.

Monsuwe, T. P. y., Dellaert, B. G. C. \& Ruyter, K. d. (2004) What drives consumer to shop online? A literature review. International Journal of Service Industry Management, 15(1), 102-121. https://doi.org/10.1108/09564230410523358. 
Mor, V. (2014) A framework for understanding regulation of long-term care quality. IN V. Mor, T. Leone \& A. Maresso (Eds.) Regulating long-term care quality: An international comparison. Cambridge University Press, Cambridge

Municipal Government of Beijing (2009) Regulations on home and community-based care for older people in Beijing (beijingshi shimin jujia yanglao (zhucan) fuwu ('jiuyang') banfa), Bureau of Civil Affairs, Beijing. Available at: http://www.gov.cn/gzdt/2009-12/17/content_1489588.htm. Accessed on 10 August 2018.

Municipal Government of Hangzhou (2013) Advice on implementing the social care policy for older people (hangzhoushi yanglao fuwu butie zhidu yijian), Bureau of Civil Affairs, Hangzhou. Available at: http://hz.zjzwfw.gov.cn/art/2014/9/26/art_71136_931.html. Accessed on 09 August 2018.

Municipal Government of Shanghai (2016) A report of social care for older people in Shanghai (shanghai yanglao fuwu fazhan baogao), Shanghai People's Publishing House, Shanghai.

Municipal Government of Tianjin (2017) Notification on changing the level of subsidies of home and community-based care services (guanyu tiaozheng woshi jujia yanglao fuwu (huli) butie biaozhun de tongzhi), Bureau of Civil Affairs and Bureau of Finance, Tianjin. Available at: http://mz.tj.gov.cn/zwgk/system/2017/03/21/030008466.shtml. Accessed on 09 August 2018.

Murphy, C. M., Whelan, B. J. \& Normand, C. (2015) Formal home-care utilisation by older adults in Ireland: Evidence from the Irish Longitudinal Study on Ageing. Health and Social Care in the Community, 23(4), 408-418. https://doi.org/10.1111/hsc.12157.

Otero, A., Yebenes, M. J. G. d., Rodriguez-Laso, A. \& Zunzunegui, M. V. (2003) Unmet home care needs among community-dwelling elderly people in Spain. Aging Clinical and Experimental Research, 15(3), 234-242. https://doi.org/10.1007/BF03324504.

Peng, R., Wu, B. \& Ling, L. (2015) Undermet needs for assistance in personal activities of daily living among community-dwelling oldest old in China from 2005 to 2008. Research on Aging, 37(2), 148170. http://doi.org/10.1177/0164027514524257.

Rabe-Hesketh, S. \& Skrondal, A. (2012) Multilevel and Longitudinal Modeling Using Stata, A Stata Press Publication, Texas.

Roelands, M., Van Oyen, H., Depoorter, A. \& Baro, F. (2003) Are cognitive impairment and depressive mood associated with increased service utilisation in community-dwelling elderly people? Health and Social Care in the Community, 11(1), 1-9. https://doi.org/10.1046/j.1365-2524.2003.00401.x.

Silverstein, M., Cong, Z. \& Li, S. (2006) Intergenerational transfers and living arrangements of older people in rural China: consequences for psychological well-being. Journal of Gerontology: Social Sciences, 61B(5), S256-S266. https://doi.org/10.1093/geronb/61.5.S256.

State Council (2011) The 12th five-year forward plan of social and economic development (guomin jingji he shehui fazhan shierwu guihua gangyao), State Council, Beijing. Available at: http://www.gov.cn/2011h/content_1825838_2.htm. Accessed on 09 August 2018. 
State Council (2013) Some advice on promoting the development of services for older people (guowuyuan guanyu jiakuai fazhan yanglao fuwuye de ruogan yijian), State Council, Beijing. Available at: http://www.gov.cn/zwgk/2013-09/13/content_2487704.htm. Accessed on 07 August 2018.

State Council (2016) Advice on opening the market of older people's services and improving the quality of services (guanyu quanmian fangkai yanglao fuwu shichang tisheng fuwu zhiliang de ruogan yijian), State Council, Beijing. Available at: http://www.gov.cn/zhengce/content/201612/23/content_5151747.htm. Accessed on 03 September 2018.

Stoddart, H., Whitley, E., Harvey, I. \& Sharp, D. (2002) What determines the use of home care services by elderly people? Health and Social Care in the Community, 10(5), 348-360. https://doi.org/10.1046/j.1365-2524.2002.00380.x.

Ten Ministries (2006) Advice on promoting the development of services for older people (guanyu jiakuai fazhan yanglao fuwuye de yijian), Ten Ministries, Beijing. Available at: http://www.gov.cn/zwgk/2006-02/17/content_202553.htm. Accessed on 30 August 2018.

Tesch-Romer, C. \& Wahl, H.-W. (2017) Towards a more comprehensive concept of successful aging: Disability and care needs. Journals of Gerontology: Social Sciences, 72(2), 310-318. https://doi.org/10.1093/geronb/gbw162.

Three Ministries (2017) Action plans on developing the smart and healthy ageing industry, 2017-2020 (zhihui jiankang yanglao chanye fazhan xingdong jihua, 2017-2020), Ministry of Industry and Information Technology, Ministry of Civil Affairs, and National Health Commission, Beijing. Available at: http://www.gov.cn/xinwen/2017-02/20/content_5169385.htm\#allContent. Accessed on 03 September 2018.

Tong, C. \& Wang, L. (2015) The government responsibilities for home and community-based care services: The perspective of welfare pluralism (fuli duoyuan zhuyi shijiao xia woguo jujia yanglao fuwu de zhengfu zeren tixi goujian). Northwest Population, 36(1), 73-84.

United Nations (2017) World population prospects 2017, United Nations Population Division, New York. Available at: https://esa.un.org/unpd/wpp/DataQuery/. Accessed on 07 August 2018.

Vergrugge, L. M. \& Jette, A. M. (1994) The disablement process. Social Science and Medicine, 38(1), 1-14. https://doi.org/10.1016/0277-9536(94)90294-1.

Vlachantoni, A., Shaw, R. J., Evandrou, M. \& Falkingham, J. (2015) The determinants of receiving social care in later life in England. Ageing and Society, 35(2), 321-345. https://doi.org/10.1017/S0144686X1300072X.

Woetzel, J., Seong, J., Wang, K. W., Manyika, J., Chui, M. \& Wong, W. (2017) China's digital economy: a leading global force, McKinsey Global Institute, Shanghai. Available at: https://www.mckinsey.com/ /media/mckinsey/featured\%20insights/China/Chinas\%20digital\%20econ omy $\% 20 \mathrm{~A} \% 20$ leading\%20global\%20force/MGI-Chinas-digital-economy-A-leading-globalforce.ashx. Accessed on 09 October 2018.

Wu, B., Carter, M. W., Goins, R. T. \& Cheng, C. (2005) Emerging services for community-based longterm care in urban China. Journal of Aging and Social Policy, 17(4), 37-60. https://doi.org/10.1300/J031v17n04_03. 
Xu, Q. \& Chow, J. C. (2011) Exploring the community-based service delivery model: elderly care in China. International Social Work, 54(3), 374-387. http://doi.org/10.1177/0020872810396260.

Zhang, N. J., Guo, M. \& Zheng, X. (2012) China: awakening giant developing solutions to population aging. The Gerontologist, 52(5), 589-596. https://doi.org/10.1093/geront/gns105.

Zhang, X., Prybutok, V. \& Huang, A. (2006) An empirical study of factors affecting e-service satisfaction. Human Systems Management, 25(4), 279-291.

Zhu, D., He, W. \& Tian, F. (2018) Social life within here: how SNS empowers different generations in China, Social Sciences Academic Press (China), Beijing. 